\title{
Patient-derived breast tumor xenografts facilitating personalized cancer therapy
}

\author{
Melissa D Landis*, Brian D Lehmann², Jennifer A Pietenpol ${ }^{2}$ and Jenny C Chang ${ }^{1,3 *}$
}

\begin{abstract}
Despite improved detection and reduction of breast cancer-related deaths over the recent decade, breast cancer remains the second leading cause of cancer death for women in the US, with 39,510 women expected to succumb to metastatic disease in 2012 alone (American Cancer Society, Cancer Facts \& Figures 2012. Atlanta: American Cancer Society; 2012). Continued efforts in classification of breast cancers based on gene expression profiling and genomic sequencing have revealed an underlying complexity and molecular heterogeneity within the disease that continues to challenge therapeutic interventions. To successfully identify and translate new treatment regimens to the clinic, it is imperative that our preclinical models recapitulate this complexity and heterogeneity. In this review article, we discuss the recent advances in development and classification of patient-derived human breast tumor xenograft models that have the potential to facilitate the next phase of drug discovery for personalized cancer therapy based on the unique driver signaling pathways in breast tumor subtypes.
\end{abstract}

Recent advances in genomics, transcriptomics, and proteomics have given us more insight into and understanding of cancer genetics. With this accumulation of knowledge, it has become apparent that cancer etiology is extremely complex and heterogeneous; even within a single organ such as breast, multiple subtypes of cancer have been identified. It is imperative that our therapeutic strategies address the complexity and heterogeneity within the disease. Rodent tumor models have been generated since the 1960s, with xenografted human tumor models emerging in the 1980s (reviewed in [1]).

\footnotetext{
*Correspondence: mdlandis@tmhs.org; jcchang@tmhs.org

'The Methodist Cancer Center, Houston, TX 77030, USA

Full list of author information is available at the end of the article
}

However, only recently have technological advances allowed comparison of xenografted tumors to primary patient tumors at a level previously unobtainable, allowing the subtype classification of patient-derived xenograft (PDX) tumors. Additionally, new technologies such as intravital microscopy show unique conserved morphology and vascularization compared to injected cell lines, thus allowing prediction and optimization of therapeutic strategies based on tumor biology.

Although breast cancer cell lines are informative and have been widely used due to their well-defined characteristics, they do not adequately reflect breast cancer heterogeneity or morphology in vivo and are poorly metastatic from the orthotopic site, thus limiting their predictive value in the clinical setting [2-4]. In contrast, PDXs retain morphology, cellular heterogeneity, and molecular profiles of the original patient tumors [1,4-9]. Currently, xenografts from patient derived-tumors have proven to be an effective model for screening potential chemotherapeutics and translating to efficacy in clinical trials $[2,5,10,11]$. To evaluate the efficacy of potential therapeutics, PDXs provide the ability to place the same 'patient' on all arms of a trial in preclinical studies. The key to successfully identifying novel cancer therapies will be selecting representative models, recognizing limitations of each model, and evaluating the correct endpoints that reflect therapeutic efficacy. With recent efforts to fully characterize unique PDX lines by molecular subtyping and mutation analysis, we are well poised to initiate studies that can identify subsets of patients that will potentially respond to novel cancer therapies, thus bringing us several steps closer to personalized medicine.

\section{Recent advances in patient-derived xenograft models}

The proven predictive ability and translation of cancer therapies from PDX tumor models has led to a renewed interest in developing PDX models [2,5,10-12]. Previous improvements in engraftment approaches, including orthotopic transplantation into the mammary fat pad, co-injection of basal membrane extract, and utilization of more severely immunocompromised mouse models, set the stage for advances in generating PDX cohorts from 
human breast tumors [13-16]. Several groups, including ours, have generated stable cohorts of breast cancer PDXs (Table 1) [1,6,8,9,11,17-22]. For this review, we will focus on academic, rather than commercial, stable breast tumor PDX cohorts.

Initially, additional immunosuppression by pretreatment with etoposide or irradiation was used to prevent host-graft rejection. Although breast tumor xenografts had proven to be quite challenging, Visonneau and colleagues [1] transplanted 16 patient biopsies subcutaneously into etoposide-pretreated severe combined immunodeficiency (SCID) mice, achieving a 50\% take rate with systemic spread and serial passage of two lines. In addition, they reported that transplantation of an aggressive metastatic xenograft into non-obese diabetic/ severe combined immunodeficiency (NOD/SCID) mice reduced metastasis, and soluble IL-2 receptor levels in the serum had a strong correlation with tumor load. Using a similar engraftment approach, Al Hajj and colleagues [17] transplanted patient tumors into the thoracic mammary gland fat pad of etoposide- and estrogen-pretreated NOD/SCID mice, thereby identifying a tumorigenic subpopulation of breast cancer cells. Notably, eight of these nine xenografts were derived from pleural effusions (PEs), indicating high take rate from metastatic sites. More recently, they generated additional models from primary tumors and metastatic sites, with the majority of these PDXs generating lung micrometastases [19]. Beckhove and colleagues [18] found that sub-lethal irradiation (3.75 Gy) to further suppress the immune system increased NOD/SCID mouse mortality compared to non-irradiated mice, without improving the engraftment rate or tumor marker expression of intramuscularly implanted tumor tissue (Table 1; 93 versus $90 \%$ take rate, respectively). Both methods retained cytokeratin expression and induced host stromal cytokine expression similar to the original patient tumors, yet the non-irradiated hosts had more leukocyte infiltration into the tumors, leading to the conclusion that additional immunosuppression is not necessary for engraftment and may reduce important microenvironmental interactions.

Several groups have since reported successful engraftment without further immune suppression (Table 1). By subcutaneously transplanting into the subscapular fatpad of estrogen-treated Swiss nude mice, Marangoni and colleagues [6] achieved a $15 \%$ and $24 \%$ initial engraftment rate from primary tumors and metastatic sites, respectively. These Swiss nude mouse models produced a $12.5 \%$ stable take rate (25/200) and ten models with lung metastases. In comparing xenograft response to patient response to treatment, a 5/7 concordance was observed, supporting the utility of these models for evaluating therapeutics. This French group has continued to lead efforts in PDXs, generating the first panel of luminal breast cancer xenografts and extensive molecular profiling of PDXs $[21,23]$. These luminal models recapitulated heterogeneous clinical behaviors with varying sensitivities to hormone therapies [21]. Bergamaschi and colleagues [24] replaced Swiss nude mice with SCID mice to achieve a $20 \%$ initial take rate and establish two stable lines (7\% stable take rate). Estrogen supplementation and transplantation into the interscapular fatpad have proven to be effective approaches to establishing PDXs.

Other groups have successfully employed orthotopic transplantation into the cleared mammary gland fat pad of SCID mice without additional immunosuppression (Table 1). DeRose and colleagues had an initial engraftment rate of $37 \%$ and a stable take rate of $24 \%$ from 4 primary tumors, 7 pleural effusates, and 1 ascites [8]. The majority of these tumor grafts developed metastases with frequencies from $38 \%$ to $100 \%$ in sites corresponding to patient metastatic sites, recapitulating the original patient metastatic cascade. They also showed that implantation of human mesenchymal stem cells with tumors improved tumor growth and stability by enhancing tumor vascularization and preserved estrogen receptor (ER) expression. Zhang and colleagues [9] established a large cohort of 35 stable lines representing 27 independent patients, with 12 lines (48\%) developing metastatic lesions in the lungs. Low dose estrogen supplementation without exogenous human fibroblasts proved to be the most conducive condition for establishing PDXs. Kabos and colleagues [20] developed five stable luminal PDXs that retained hormone receptor expression after serial transplantation and reflected clinical heterogeneity with estrogen-dependent gene signatures. Interestingly, estrogen supplementation has improved take rate and enhanced tumor growth regardless of hormone receptor status in the tumor cells [25-27]. This may be explained by a recent report suggesting estrogen stimulation of ER-negative tumor growth is, in part, due to ER $\alpha$-mediated effects on bone marrow-derived myeloid cells that promote angiogenesis and tumor growth [27].

The various SCID models (SCID, SCID/Beige, NOD/ SCID/IL2 $\gamma$-receptor null (NSG)) have been equally successful $[1,6,8,9,17,19]$, but the nude $(\mathrm{nu})$ mutation or combined bg/nu/xid mutation mice had been relatively resistant to initial engraftment of human breast tumors [1] until Marangoni and colleagues [6] achieved success with Swiss nude mice. In general, SCID models are more permissive to systemic spread (Table 1 ) $[8,9,19]$. This is likely due to the increased severity and stability of immunodepletion in the SCID models compared to the nude mice. Whereas initial reports found no correlation between engraftment and pathological diagnosis, grading, or ER/progesterone receptor (PR) status [1], several groups since have found that take rate correlates with 


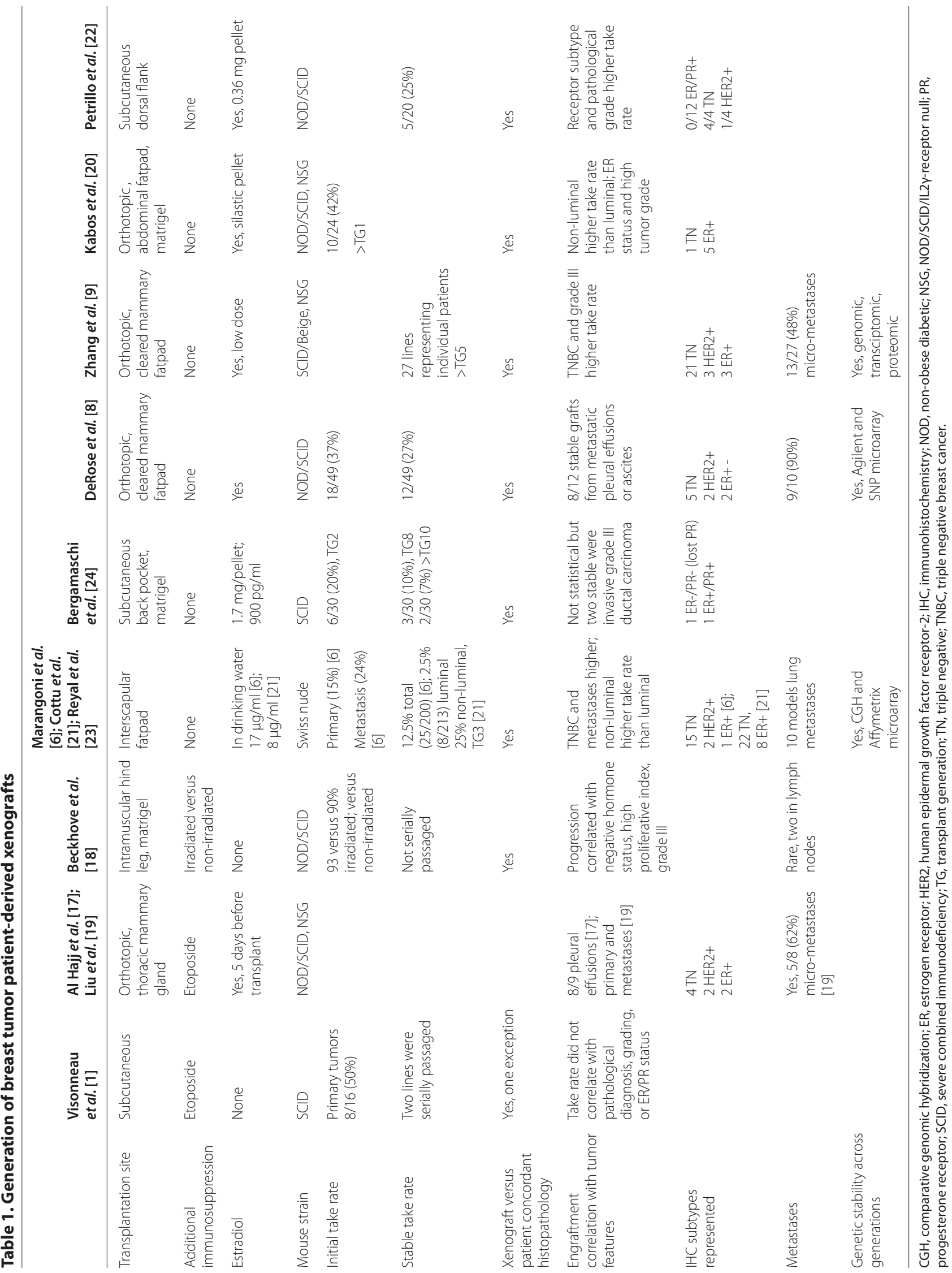


tumor grade, with the most aggressive grade III and IV triple negative breast cancers (TNBCs) having higher take rates than ER+ tumors (Table 1) [6,9,18,21,22,24]. Accordingly, the cohorts of PDXs have been inherently biased towards TNBC until recent efforts focused on generating luminal cohorts [20,21]. Moreover, metastatic lesions generally have higher take rates than primary tumors $[6,8]$.

Regardless of the challenges in establishing PDX, these models generally retain the pathological characteristics and biomarker status of the original patient tumor and have proven to be stable across multiple transplant generations. Several groups have documented retention of histopathological characteristics and biomarker status by evaluating original patient tumors and corresponding PDXs in subsequent generations by standard hematoxylin and eosin staining and immunohistochemistry (IHC) techniques for ER, PR, human epidermal growth factor receptor-2 (HER2), and proliferative index (Ki67) (Table 1) [1,8,9,18-23]. Genomic analysis by paired-end sequencing, comparative genomic hybridization, and SNP as well as transciptomic evaluation by Affymetrix and Agilent gene expression analysis show shared alterations between primary and xenograft tumors, with more pronounced mutational status or aggressiveness tumor characteristics in PDXs (Table 2) [7,8,21-24]. By comparing deep sequencing results of a basal-like TN patient breast tumor, blood, metastasis and PDX, Ding and colleagues [7] found that the PDX retained the mutations of the primary tumor and gained additional mutations comparable to the patient metastasis. In another example, genomic analysis of one patient tumor had one wild-type TP53 allele with the corresponding xenograft having loss-of-heterozygosity in TP53, and an ER+ tumor gained basal-like alterations [24]. Reyal and colleagues [23] reported less than $5 \%$ of genes had recurrent variation between patient tumors and xenografts; not surprisingly, these genes corresponded to human stromal compartment genes. In summary, these highly characterized PDX models serve as a renewable resource of human breast tumor tissue and preclinical models for preclinical evaluation of novel cancer therapies.

\section{Therapeutic application of breast tumor patient- derived xenografts}

Although breast cancer cell lines are widely used for mechanistic and therapeutic studies due to their welldefined characteristics, they do not adequately reflect breast cancer heterogeneity or morphology in vivo, thus limiting their predictive value. Furthermore, most breast cancer cell lines when orthotopically injected do not efficiently metastasize and require tail vein injection to generate contrived metastatic models. In contrast, PDXs retain the morphology, cellular heterogeneity, and molecular profiles of the original patient tumors [1,49,20-22], thereby being relevant preclinical models to identify effective therapeutic regimens that can be translated into clinical practice. PDXs recapitulate the heterogeneity of treatment response as seen in the clinic and show concordance with the original patient's treatment response [6,20,21]. Additionally, the orthotopic transplant models have proven to efficiently recapitulate human metastatic lesions and sites (Table 1). Translating preclinical data to the clinic requires appropriate selection of representative models, recognition of intrinsic limitations for each model, and selection of the appropriate endpoints to identify effective therapeutic regimens.

While the applications and utility of PDXs are enormous, it is important to recognize the limitations of these PDXs in interpreting results. The two fundamental limitations of PDXs are the mouse microenvironment and the lack of an intact immune system. In contrast to human breast epithelium that is surrounded by intra- and inter-lobular stroma and has minimal contact with adipose tissue, mouse breast epithelium is embedded mostly in adipose tissue with interspersed connective tissue [28]. In the PDX models, stromal components within the tumor are actually better than expected; the tumor epithelium is able to effectively communicate with the mouse stroma to recapitulate the histopathogical characteristics of the patient original tumor. Mouse connective tissue and other stromal components are interspersed in the tumor epithelium $[8,23]$. That being said, it is uncertain how closely the mouse and human cell interactions resemble that of the human stroma/ human tumor, and exactly what components are missing. Several successful efforts to recapitulate human breast stroma in mice have been reported [29,30]. It has been shown that normal fibroblasts can inhibit transformed mammary epithelial cell growth [31]; therefore, it will be critical to properly match tumor-associated stroma. In our hands, implanting irradiated human fibroblasts actually reduced stable take rate of human breast tumors. Although generating PDXs with humanized stroma components can improve the evaluation of microenvironmental influences on treatment response for a limited number of models [32], technical challenges of matching each tumor with its own stromal components currently precludes generation of large cohorts for preclinical testing.

Additionally, these models lack an intact immune system, which can play both a prohibitive and activating role in tumor development and therapeutic response (reviewed in [33]). Well-defined genetically engineered mouse models that represent the heterogeneity and complexity of tumor etiology, such as TP53 null tumor models, will be essential in evaluating immunological 
Table 2. Genomic and transcriptomic evaluation of breast tumor patient-derived xenografts

\begin{tabular}{|c|c|c|c|c|c|c|}
\hline & $\begin{array}{l}\text { Marangoni et al. [6]; } \\
\text { Cottu et al. [21]; } \\
\text { Reyal et al. [23] }\end{array}$ & $\begin{array}{l}\text { Bergamaschi } \\
\text { et al. [24] }\end{array}$ & $\begin{array}{l}\text { Ding } \\
\text { et al. [7] }\end{array}$ & $\begin{array}{l}\text { DeRose } \\
\text { et al. [8] }\end{array}$ & $\begin{array}{l}\text { Kabos } \\
\text { et al. [20] }\end{array}$ & $\begin{array}{l}\text { Petrillo } \\
\text { et al. [22] }\end{array}$ \\
\hline $\begin{array}{l}\text { Microarray- } \\
\text { gene } \\
\text { expression }\end{array}$ & $\begin{array}{l}\text { Gene expression analysis } \\
\text { (GEA) }\end{array}$ & $\begin{array}{l}\text { Agilent GEA } \\
\text { High dose E2 } \\
\text { supplementation } \\
\text { altered gene expression }\end{array}$ & $\begin{array}{l}\text { PAM50 intrinsic subtype } \\
\text { classification }\end{array}$ & $\begin{array}{l}\text { Agilent GEA, intrinsic } \\
\text { subtype classification, } \\
\text { PAM50 confirmation }\end{array}$ & $\begin{array}{l}\text { Agilent GEA, } \\
\text { PAM50 intrinsic } \\
\text { subtype } \\
\text { classification }\end{array}$ & $\begin{array}{l}\text { Agilent GEA, } \\
\text { PAM50 intrinsic } \\
\text { subtype } \\
\text { classification }\end{array}$ \\
\hline $\begin{array}{l}\text { Intrinsic } \\
\text { subtypes } \\
\text { represented }\end{array}$ & $\begin{array}{l}\text { Basal-like (5) } \\
\text { Luminal A (2) } \\
\text { Luminal B (1) [23] }\end{array}$ & $\begin{array}{l}\text { Basal-like (1) } \\
\text { Luminal B (1) }\end{array}$ & Basal-like (1) & $\begin{array}{l}\text { Basal-like (4) } \\
\text { HER2-like (1) } \\
\text { Luminal B (4) } \\
\text { Normal-like (1) }\end{array}$ & $\begin{array}{l}\text { Basal-like (1) } \\
\text { HER2-like (1) } \\
\text { Luminal B (4) }\end{array}$ & $\begin{array}{l}\text { Basal-like (3) } \\
\text { Luminal A (1) }\end{array}$ \\
\hline
\end{tabular}

CGH, comparative genomic hybridization; ER, estrogen receptor; GEA, gene expression analysis; HER2, human epidermal growth factor receptor-2; LOH, loss of heterozygosity; PDX, patient-derived xenograft.

effects on tumor development and therapeutic response [34]. Additional efforts are ongoing to humanize the immune system in mice [35,36]; however, to prevent rejection of xenografts, the humanized immune cells have to precisely match the tumor, thus restricting large cohort development currently.

Finally, identification of novel therapeutics in preclinical models requires appropriate end point evaluation. Recent ARRIVE (Animals in Research: Reporting In Vivo Experiments) guidelines provide a thorough checklist of 20 items, from experimental design to statistical analysis, that should be included to improve the quality of reports and interpretation of results from animal studies [37]. In considering study endpoints to be evaluated, generally tumor volume and toxicity measurements are standard methods of monitoring treatment effects. Tumor growth rate should be considered for determining treatment duration in detecting a significant response in tumor growth. Based on therapy resistance and increasing evidence supporting the cancer stem cell (CSC) hypothesis [3840], tumor recurrence after treatment cessation and functional CSC assays can also be critical endpoints in evaluating treatment response to targeted therapies. Recurrence studies replicate the clinical setting with multiple treatment cycles [3-6], while monitoring body weight and tumor volume to report time to elimination of tumors and time to recurrence after cessation of treatment.
According to the CSC hypothesis, tumor cells exist in a hierarchy with a select population, that is, CSCs or tumor-initiating cells, being responsible for initiation and recurrence of tumors. To monitor effects on CSCs, tumors are collected for downstream CSC assays, including mammosphere formation efficiency, flow cytometric analysis of CSC markers, and limiting dilution retransplantation of treated tumor cells. Recent reports have evaluated one to three PDX lines and complemented with two to three cell line xenografts to evaluate potential cancer therapies, and define mechanisms underlying treatment response or resistance [41-43]. This is due, in part, to the inherent challenges of isolating viable cells after dissociation of solid tumors for downstream assays. Additionally, the labor involved and financial considerations are likely to limit the number of lines evaluated in this manner. Not all tumor lines retain viability and functional capacity after dissociation, with the more aggressive metastasis-derived lines being more amenable to manipulations. Recently, we overcame the challenge of limited cell viability inherent in dissociation of solid tumors by transplanting equal size, intact fragments (10 mg containing $1 \times 10^{5}$ cells) and monitoring tumor initiation with or without targeted treatment to successfully detect inhibition of tumor initiation with treatment. Efforts are still underway to improve isolation of single cell suspensions so that all tumor lines can be evaluated by downstream functional assays such as CSC assays, 
epithelial-to-mesenchymal transition assays, and flow cytometric measurement of signaling pathways within different cell types.

Since the availability of PDX lines has expanded and these tumors have been fully characterized by the efforts of multiple groups, it is now possible to carry out preclinical clinical trials in which a panel of tumors representing individual patients is assigned to each arm of a study for direct comparison of treatment strategies. Moreover, with molecular profiling, treatment response can be evaluated according to subtype classification.

\section{Molecular subtyping of breast tumor patient-derived xenografts}

Molecular profiling has identified at least six intrinsic breast cancer subtypes (luminal A, luminal B, HER2enriched, basal-like, claudin-low, and a normal-like group) with clinically significant differences in risk factors, incidence, and baseline prognosis, and treatment response [44-49]. Molecular subtypes more accurately predict clinical response than standard pathological staging and immunohistochemical classification of tumors by ER, PR, HER2, and Ki67 expression [47,50,51]. To determine the intrinsic tumor subtypes of breast tumor PDX, the Welm group carried out global gene expression microarray analysis and then performed hierarchical clustering with the UNC337 human dataset that represents the intrinsic molecular subtypes $[47,49]$. Similar classifications were shown using the PAM50 supervised subtype predictor $[47,48]$. Breast tumor PDX clustered within the intrinsic subtypes of breast cancer rather than forming a separate cluster (Table 2) [8,22,23]. Furthermore, these PDX models displayed genetic stability, as original human tumors and multiple generations of xenografts clustered together, reflecting shared gene expression between PDXs and patient tumors $[8,22,23]$. Not all intrinsic breast tumor subtypes are equally represented by the current PDX lines, with a bias toward the basal-like subtype (Table 2). This is due to increased engraftment rate from late stage and metastatic tumors, which tend to be TN and HER2+ (Table 1). Luminal tumors, which inherently have lower pathological grades and slower growth rates, have historically been difficult to establish. Although the take rates of ER+ tumors are much lower compared to TN (2.5\% versus $25 \%$ [21]), recent efforts focusing on generation of luminal tumors has increased the number of stable luminal PDXs $[20,21]$. DeRose and colleagues [8] established four luminal B PDXs with human mesenchymal stem cell cotransplantation. Despite these efforts, luminal A tumors still have limited numbers amongst the established PDX lines (Table 2). As PDX model development continues, the representation of each of the intrinsic breast tumor subtypes should become more comprehensive.
Table 3. Pietenpol triple negative breast cancer subtype classification of patient-derived xenografts

\begin{tabular}{lcc}
\hline & $\begin{array}{c}\text { Patient-derived } \\
\text { xenograft lines }\end{array}$ & $\begin{array}{c}\text { Pietenpol triple negative } \\
\text { breast cancer subtype }\end{array}$ \\
\hline 1 & BCM-2147/2277 & BL1 \\
2 & BCM-2665A & BL1 \\
3 & BCM-3611/3824 & BL1 \\
4 & BCM-3904 & BL1 \\
5 & BCM-4664 & BL1 \\
6 & BCM-4913/5438 & BL1 \\
7 & BCM-3936 & BL1/UNC \\
8 & BCM-4175 & M \\
9 & BCM-4272/4849 & UNC/BL1 \\
10 & BCM-3807/4400 & IM/BL2 \\
11 & BCM-3107 & M \\
12 & $B C M-3204$ & M \\
13 & $B C M-3887$ & UNC \\
14 & BCM-4013 & UNC \\
15 & BCM-3561 & UNC \\
\hline
\end{tabular}

Pietenpol classification [52,53]: BL1, basal-like 1; BL2, basal-like 2; IM, immunomodulatory; M, mesenchymal-like; MSL, mesenchymal stem-like; UNC, unclassified.

TNBC describes not a single tumor type but a diverse group of cancers requiring distinct targeted therapies. Lehmann and colleagues [52] identified six unique TNBC subtypes with unique molecular profiles and ontologies that can inform therapy selection in TNBC, including: basal-like 1 and 2 (BL1 and BL2), immunomodulatory (IM), mesenchymal (M), mesenchymal stem cell-like (MSL), and luminal androgen receptor (LAR). We used their methods to determine the subtype of 15 TNBC PDXs: most (8 of 15) classified as BL1 (Table 3; unpublished observations). While the most frequently occurring subtypes $(\mathrm{BL} 1=8, \mathrm{M}=3$ and $\mathrm{BL} 2 / \mathrm{IM}=1$ ) were identified in our PDX models of TNBC, it is only a matter of time before it can be determined if all of the Pietenpol subtypes are represented in PDXs, as they have developed a user-friendly web-based application, 'TNBCtype', in which researchers can classify their samples [53]. Altogether, Perou intrinsic subtype classification and Pietenpol TNBC classification of PDX cohorts has the potential to further classify PDXs, identify novel treatment regimens, and facilitate appropriate patient selection for clinical trials.

\section{Conclusion}

Personalized medicine is intended to select subsets of patients that will most likely respond to treatment regimens, thus reducing morbidity and mortality from ineffective treatments. To identify targeted therapies and 


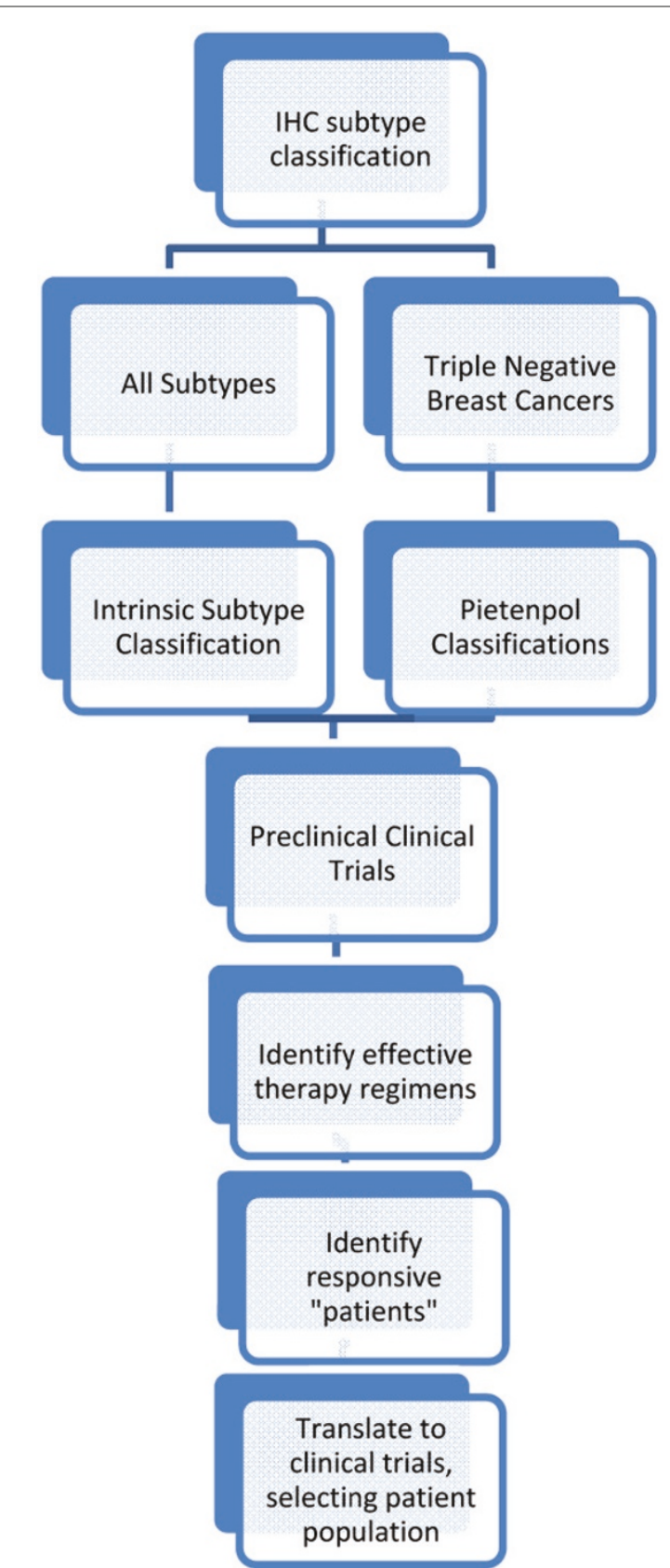

Figure 1. Schematic of preclinical clinical trials: from classification to patient selection for clinical trials. Based on the advances in generating patient-derived xenografts and breast cancer subtyping, preclinical trials can be designed to provide subtypespecific outcome data and to identify molecular profiles of tumors that respond to specific therapies, thus having the potential to better guide patient selection for clinical trials and to reduce costs and ineffective treatment options for patients. Patient-derived xenografts are subtyped by standard immunohistochemistry $(\mathrm{IHC})$ and by molecular profiling and then placed on each arm of a preclinical clinical trial for direct comparison of treatment strategies. The treatment response is then correlated with subtype classification to identify the responsive versus non-responsive tumor subtypes that correspond to patient tumor subtypes to guide selection for clinical trials. effective treatment regimens based on subtype classification, representative breast tumor PDXs can be assigned to each arm of a preclinical clinical trial (Figure 1). Integration of in vivo models of PDXs, TP53 genetically engineered mouse tumor models, and representative cell line-derived xenograft tumors will allow representation of the full range of subtypes and tumor heterogeneity. Alternatively, preclinical clinical trials may focus on TNBC using the Pietenpol TNBC subtypes to identify the subtypes responsive to different treatment regimens. Based on the complexity of signaling pathways driving tumorigenesis and/or metastasis, cocktails of inhibitors will ultimately be required to prevent recurrence and treatment resistance. In the near future, the knowledge gained by the ongoing efforts of genomic classification from complete genome sequencing of patient tumors and PDX is expected to drive the next generation of preclinical clinical trials aimed at personalizing cancer therapy.

\section{Abbreviations}

CSC, cancer stem cell; ER, estrogen receptor; HER2, human epidermal growth factor receptor-2; $I H C$, immunohistochemistry; IL, interleukin; NOD, non-obese diabetic; NSG, NOD/SCID/IL2Y-receptor null; PDX, patient-derived xenograft; $P E$, pleural effusion; $P R$, progesterone receptor; $S C I D$, severe combined immunodeficiency; SNP, single nucleotide polymorphism; TNBC, triple negative breast cancer.

\section{Competing interests}

MDL has no competing interests. AP and BDL have no competing interests directly related to content of the manuscript. There is a provisional patent for use of select genomic alterations in subtyping patients for clinical alignment with therapy, but does not include use of any model systems for prediction of therapy in the preclinical setting as presented in this manuscript. JCC has a patent for described PDX models [9] and is co-founder of StemMed, Inc.

\section{Acknowledgements}

This work was supported in part by the Breast Cancer Research Foundation, $\mathrm{NIH/NCl}$ grant R01 CA112305, and NIH/NCl grant U54 CA149196.

\section{Author details}

'The Methodist Cancer Center, Houston, TX 77030, USA. ${ }^{2}$ Department of Biochemistry, Vanderbilt-Ingram Cancer Center, Vanderbilt University School of Medicine, Preston Research Building, 2200 Pierce Avenue, Nashville, TN 37232, USA. ${ }^{3}$ Weill Cornell Medical School, NY, NY 10065, USA.

Published: 22 January 2013

\section{References}

1. Visonneau S, Cesano A, Torosian MH, Miller EJ, Santoli D: Growth characteristics and metastatic properties of human breast cancer xenografts in immunodeficient mice. Am J Pathol 1998, 152:1299-1311.

2. Voskoglou-Nomikos T, Pater JL, Seymour L: Clinical predictive value of the in vitro cell line, human xenograft, and mouse allograft preclinical cancer models. Clin Cancer Res 2003, 9:4227-4239.

3. Clarke $R$ : The role of preclinical animal models in breast cancer drug development. Breast Cancer Res 2009, 11 Suppl 3:S22.

4. Hait WN: Anticancer drug development: the grand challenges. Nat Rev Drug Discov 2010, 9:253-254.

5. Boven E, Winograd B, Berger DP, Dumont MP, Braakhuis BJ, Fodstad O, Langdon S, Fiebig HH: Phase II preclinical drug screening in human tumor xenografts: a first European multicenter collaborative study. Cancer Res 1992, 52:5940-5947.

6. Marangoni E, Vincent-Salomon A, Auger N, Degeorges A, Assayag F, de Cremoux P, de Plater L, Guyader C, De Pinieux G, Judde JG, Rebucci M, 
Tran-Perennou C, Sastre-Garau X, Sigal-Zafrani B, Delattre O, Diéras V, Poupon MF: A new model of patient tumor-derived breast cancer xenografts for preclinical assays. Clin Cancer Res 2007, 13:3989-3998.

7. Ding L, Ellis MJ, Li S, Larson DE, Chen K, Wallis JW, Harris CC, McLellan MD, Fulton RS, Fulton LL, Abbott RM, Hoog J, Dooling DJ, Koboldt DC, Schmidt H, Kalicki J, Zhang Q, Chen L, Lin L, Wendl MC, McMichael JF, Magrini VJ, Cook L, McGrath SD, Vickery TL, Appelbaum E, Deschryver K, Davies S, Guintoli T, Lin $L$, et al: Genome remodelling in a basal-like breast cancer metastasis and xenograft. Nature 2010, 464:999-1005.

8. DeRose YS, Wang G, Lin YC, Bernard PS, Buys SS, Ebbert MT, Factor R, Matsen C, Milash BA, Nelson E, Neumayer L, Randall RL, Stijleman IJ, Welm BE, Welm AL: Tumor grafts derived from women with breast cancer authentically reflect tumor pathology, growth, metastasis and disease outcomes. Nat Med 2011, 17:1514-1520.

9. Zhang X, Dobrolecki LE, Lai Q, Landis MD, Wong H, Tsimelzon A, Claerhout S, Contreras A, Gutierrez C, Huang J, Wu M-F, Pavlick AC, Froehlich AM, Hilsenbeck SG, Mills GB, Wiechmann L, Petrovic I, Rimawi MF, Schiff R, Chang JC, Lewis MT: A renewable tissue resource of phenotypically stable human breast cancer xenografts for preclinical studies. Cancer Res 2011, 71(24 Suppl):Abstract P5-21-01.

10. Scholz CC, Berger DP, Winterhalter BR, Henss H, Fiebig HH: Correlation of drug response in patients and in the clonogenic assay with solid human tumour xenografts. Eur J Cancer 1990, 26:901-905.

11. Fiebig HH, Maier A, Burger AM: Clonogenic assay with established human tumour xenografts: correlation of in vitro to in vivo activity as a basis for anticancer drug discovery. Eur $J$ Cancer 2004, 40:802-820.

12. Decaudin D: Primary human tumor xenografted models ('tumorgrafts') for good management of patients with cancer. Anticancer Drugs 2011, 22:827-841.

13. Outzen HC, Custer RP: Growth of human normal and neoplastic mammary tissues in the cleared mammary fat pad of the nude mouse. J Natl Cancer Inst 1975, 55:1461-1466.

14. Miller BE, Miller FR, Heppner GH: Interactions between tumor subpopulations affecting their sensitivity to the antineoplastic agents cyclophosphamide and methotrexate. Cancer Res 1981, 41:4378-4381.

15. Sweeney TM, Kibbey MC, Zain M, Fridman R, Kleinman HK: Basement membrane and the SIKVAV laminin-derived peptide promote tumor growth and metastases. Cancer Metastasis Rev 1991, 10:245-254.

16. Sakakibara T, XuY, Bumpers HL, Chen FA, Bankert RB, Arredondo MA, Edge SB, Repasky EA: Growth and metastasis of surgical specimens of human breast carcinomas in SCID mice. Cancer J Sci Am 1996, 2:291-300.

17. Al-Haji M, Wicha MS, Benito-Hernandez A, Morrison SJ, Clarke MF: Prospective identification of tumorigenic breast cancer cells. Proc Natl Acad SciU S A 2003, 100:3983-3988.

18. Beckhove P, Schütz F, Diel IJ, Solomayer EF, Bastert G, Foerster J, Feuerer M, Bai $L$, Sinn HP, Umansky V, Schirrmacher V: Efficient engraftment of human primary breast cancer transplants in nonconditioned NOD/Scid mice. Int J Cancer 2003, 105:444-453.

19. Liu H, Patel MR, Prescher JA, Patsialou A, Qian D, Lin J, Wen S, Chang YF, Bachmann MH, Shimono Y, Dalerba P, Adorno M, Lobo N, Bueno J, Dirbas FM, Goswami S, Somlo G, Condeelis J, Contag CH, Gambhir SS, Clarke MF: Cancer stem cells from human breast tumors are involved in spontaneous metastases in orthotopic mouse models. Proc Natl Acad Sci U S A 2010, 107:18115-18120

20. Kabos P, Finlay-Schultz J, Li C, Kline E, Finlayson C, Wisell J, Manuel CA Edgerton SM, Harrell JC, Elias A, Sartorius CA: Patient-derived luminal breast cancer xenografts retain hormone receptor heterogeneity and help define unique estrogen-dependent gene signatures. Breast Cancer Res Treat 2012 135:415-432.

21. Cottu P, Marangoni E, Assayag F, de Cremoux P, Vincent-Salomon A, Guyader Ch, de Plater L, Elbaz C, Karboul N, Fontaine JJ, Chateau-Joubert S, BoudouRouquette P, Alran S, Dangles-Marie V, Gentien D, Poupon MF, Decaudin D: Modeling of response to endocrine therapy in a panel of human luminal breast cancer xenografts. Breast Cancer Res Treat 2012, 133:595-606.

22. Petrillo LA, Wolf DM, Kapoun AM, Wang NJ, Barczak A, Xiao Y, Korkaya H, Baehner F, Lewicki J, Wicha M, Park JW, Spellman PT, Gray JW, van't Veer L, Esserman $\sqcup$ : Xenografts faithfully recapitulate breast cancer-specific gene expression patterns of parent primary breast tumors. Breast Cancer Res Treat 2012, 135:913-922.

23. Reyal F, Guyader C, Decraene C, Lucchesi C, Auger N, Assayag F, De Plater L, Gentien D, Poupon MF, Cottu P, De Cremoux P, Gestraud P, Vincent-Salomon
A, Fontaine JJ, Roman-Roman S, Delattre O, Decaudin D, Marangoni E: Molecular profiling of patient-derived breast cancer xenografts. Breast Cancer Res 2012, 14:R11.

24. Bergamaschi A, Hjortland GO, Triulzi T, Sørlie T, Johnsen H, Ree AH, Russnes HG, Tronnes S, Maelandsmo GM, Fodstad O, Borresen-Dale AL, Engebraaten $\mathrm{O}$ : Molecular profiling and characterization of luminal-like and basal-like in vivo breast cancer xenograft models. Mol Oncol 2009, 3:469-482.

25. Gupta PB, Proia D, Cingoz O, Weremowicz J, Naber SP, Weinberg RA, Kuperwasser C: Systemic stromal effects of estrogen promote the growth of estrogen receptor-negative cancers. Cancer Res 2007, 67:2062-2071.

26. Gupta PB, Kuperwasser C: Contributions of estrogen to ER-negative breast tumor growth. J Steroid Biochem Mol Biol 2006, 102:71-78.

27. Iyer V, Klebba I, McCready J, Arendt LM, Betancur-Boissel M, Wu MF, Zhang X, Lewis MT, Kuperwasser C: Estrogen promotes ER-negative tumor growth and angiogenesis through mobilization of bone marrow-derived monocytes. Cancer Res 2012, 72:2705-2713.

28. Fleming JM, Miller TC, Meyer MJ, Ginsburg E, Vonderhaar BK: Local regulation of human breast xenograft models. J Cell Physiol 2010, 224:795-806.

29. Kuperwasser C, Chavarria T, Wu M, Magrane G, Gray JW, Carey L, Richardson A, Weinberg RA: Reconstruction of functionally normal and malignant human breast tissues in mice. Proc Natl Acad Sci U S A 2004, 101:4966-4971.

30. Wu M, Jung L, Cooper AB, Fleet C, Chen L, Breault L, Clark K, Cai Z, Vincent S, Bottega S, Shen Q, Richardson A, Bosenburg M, Naber SP, DePinho RA, Kuperwasser C, Robinson MO: Dissecting genetic requirements of human breast tumorigenesis in a tissue transgenic model of human breast cancer in mice. Proc Natl Acad Sci U S A 2009, 106:7022-7027.

31. Sadlonova A, Novak Z, Johnson MR, Bowe DB, Gault SR, Page GP, Thottassery $J V$, Welch DR, Frost AR: Breast fibroblasts modulate epithelial cell proliferation in three-dimensional in vitro co-culture. Breast Cancer Res 2005, 7:R46-59.

32. Ma CX, Cai S, Li S, Ryan CE, Guo Z, Schaiff WT, Lin L, Hoog J, Goiffon RJ, Prat A, Aft RL, Ellis MJ, Piwnica-Worms H: Targeting Chk1 in p53-deficient triplenegative breast cancer is therapeutically beneficial in human-in-mouse tumor models. J Clin Invest 2012, 122:1541-1552.

33. Coussens LM, Pollard JW: Leukocytes in mammary development and cancer. Cold Spring Harb Perspect Biol 2011, 3:pii: a003285.

34. Herschkowitz Jl, Zhao W, Zhang M, Usary J, Murrow G, Edwards D, Knezevic J, Greene SB, Darr D, Troester MA, Hilsenbeck SG, Medina D, Perou CM, Rosen $J M$ : Comparative oncogenomics identifies breast tumors enriched in functional tumor-initiating cells. Proc Natl Acad Sci U S A 2012, 109:2778-2783.

35. Lux A, Nimmerjahn F: Of mice and men: the need for humanized mouse models to study human IgG activity in vivo. J Clin Immunol 2012 [Epub ahead of print].

36. Garcia S, Freitas AA: Humanized mice: Current states and perspectives. Immunol Lett 2012, 146:1-7.

37. Kilkenny C, Browne WJ, Cuthill IC, Emerson M, Altman DG: Improving bioscience research reporting: the ARRIVE guidelines for reporting animal research. PLOS Biol 2010, 8:e1000412.

38. Schepers AG, Snippert HJ, Stange DE, van den Born M, van Es JH, van de Wetering $\mathrm{M}$, Clevers $\mathrm{H}$ : Lineage tracing reveals Lgr $5+$ stem cell activity in mouse intestinal adenomas. Science 2012, 337:730-735.

39. Driessens G, Beck B, Caauwe A, Simons BD, Blanpain C: Defining the mode of tumour growth by clonal analysis. Nature 2012, 488:527-530.

40. Chen J, Li Y, Yu TS, McKay RM, Burns DK, Kernie SG, Parada LF: A restricted cell population propagates glioblastoma growth after chemotherapy. Nature 2012, 488:522-526

41. Hoey T, Yen WC, Axelrod F, Basi J, Donigian L, Dylla S, Fitch-Bruhns M, Lazetic S, Park IK, Sato A, Satyal S, Wang X, Clarke MF, Lewicki J, Gurney A: DLL4 blockade inhibits tumor growth and reduces tumor-initiating cell frequency. Cell Stem Cell 2009, 5:168-177.

42. Ginestier C, Liu S, Diebel ME, Korkaya H, Luo M, Brown M, Wicinski J, Cabaud O, Charafe-Jauffret E, Birnbaum D, Guan JL, Dontu G, Wicha MS: CXCR1 blockade selectively targets human breast cancer stem cells in vitro and in xenografts. J Clin Invest 2010, 120:485-497.

43. Dave B, Landis MD, Tweardy DJ, and Chang JC: Selective small molecule stat 3 inhibitor reduces breast cancer tumor-initiating cells and improves recurrence free survival in a human-xenograft model. PLoS One 2012, 7:e30207.

44. Perou CM, Sørlie T, Eisen MB, van de Rijn M, Jeffrey SS, Rees CA, Pollack JR, Ross DT, Johnsen H, Akslen LA, Fluge O, Pergamenschikov A, Williams C, Zhu 
SX, Lønning PE, Børresen-Dale AL, Brown PO, Botstein D: Molecular portraits of human breast tumours. Nature 2000, 406:747-752.

45. Sørlie T, Perou CM, Tibshirani R, Aas T, Geisler S, Johnsen H, Hastie T, Eisen MB, van de Rijn M, Jeffrey SS, Thorsen T, Quist H, Matese JC, Brown PO, Botstein D, Lønning PE, Børresen-Dale AL: Gene expression patterns of breast carcinomas distinguish tumor subclasses with clinical implications. Proc Natl Acad Sci U S A 2001, 98:10869-10874.

46. Herschkowitz JI, Simin K, Weigman VJ, Mikaelian I, Usary J, Hu Z, Rasmussen KE, Jones LP, Assefnia S, Chandrasekharan S, Backlund MG, Yin Y, Khramtsov Al, Bastein R, Quackenbush J, Glazer RI, Brown PH, Green JE, Kopelovich L, Furth PA, Palazzo JP, Olopade OI, Bernard PS, Churchill GA, Van Dyke T, Perou CM: Identification of conserved gene expression features between murine mammary carcinoma models and human breast tumors. Genome Bio/ 2007, 8:R76.

47. Parker JS, Mullins M, Cheang MC, Leung S, Voduc D, Vickery T, Davies S, Fauron C, He X, Hu Z, Quackenbush JF, Stijleman IJ, Palazzo J, Marron JS, Nobel AB, Mardis E, Nielsen TO, Ellis MJ, Perou CM, Bernard PS: Supervised risk predictor of breast cancer based on intrinsic subtypes. J Clin Oncol 2009, 27:1160-1167.

48. Prat A, Parker JS, Fan C, Perou CM: PAM50 assay and the three-gene model for identifying the major and clinically relevant molecular subtypes of breast cancer. Breast Cancer Res Treat 2012, 135:301-306.

49. Prat A, Parker JS, Karginova O, Fan C, Livasy C, Herschkowitz Jl, He X, Perou CM: Phenotypic and molecular characterization of the claudin-low intrinsic subtype of breast cancer. Breast Cancer Res 2010, 12:R68.
50. van de Vijver MJ, He YD, van't Veer LJ, Dai H, Hart AA, Voskuil DW, Schreiber GJ, Peterse JL, Roberts C, Marton MJ, Parrish M, Atsma D, Witteveen A, Glas A, Delahaye L, van der Velde T, Bartelink H, Rodenhuis S, Rutgers ET, Friend SH, Bernards R: A gene-expression signature as a predictor of survival in breast cancer. N Engl J Med 2002, 347:1999-2009.

51. Paik S, Shak S, Tang G, Kim C, Baker J, Cronin M, Baehner FL, Walker MG, Watson D, Park T, Hiller W, Fisher ER, Wickerham DL, Bryant J, Wolmark N: A multigene assay to predict recurrence of tamoxifen-treated, nodenegative breast cancer. N Engl J Med 2004, 351:2817-2826.

52. Lehmann BD, Bauer JA, Chen $X$, Sanders ME, Chakravarthy AB, Shyr $Y$, Pietenpol JA: Identification of human triple-negative breast cancer subtypes and preclinical models for selection of targeted therapies. $J$ Clin Invest 2011, 121:2750-2767.

53. Chen X, Li J, Gray WH, Lehmann BD, Bauer JA, Shyr Y, Pietenpol JA: TNBCtype: A Subtyping Tool for Triple-Negative Breast Cancer. Cancer Inform 2012, 11:147-156.

doi:10.1186/bcr3355

Cite this article as: Landis MD, et al:: Patient-derived breast tumor xenografts facilitating personalized cancer therapy. Breast Cancer Research 2013, 15:201. 